Portland State University

PDXScholar

7-13-1994

\title{
The R-Stick Appliance as a Device to Facilitate the Phoneme /r/
}

Rosemary LeBlanc

Portland State University

Follow this and additional works at: https://pdxscholar.library.pdx.edu/open_access_etds

Part of the Speech and Rhetorical Studies Commons Let us know how access to this document benefits you.

Recommended Citation

LeBlanc, Rosemary, "The R-Stick Appliance as a Device to Facilitate the Phoneme /r/" (1994).

Dissertations and Theses. Paper 4794.

https://doi.org/10.15760/etd.6677

This Thesis is brought to you for free and open access. It has been accepted for inclusion in Dissertations and Theses by an authorized administrator of PDXScholar. Please contact us if we can make this document more accessible: pdxscholar@pdx.edu. 
THESIS APPROVAL

The abstract and thesis of Rosemary LeBlanc for the Master of Science in Speech Communication: Speech and Hearing Sciences were presented July 13,1994 , and accepted by the thesis committee and the department.

COMMITTEE APPROVALS:
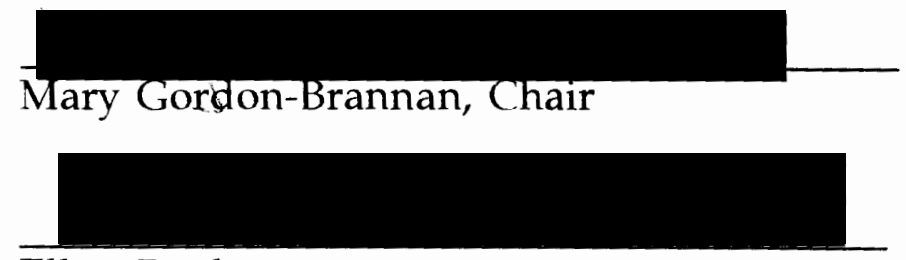

Ellen Reuler

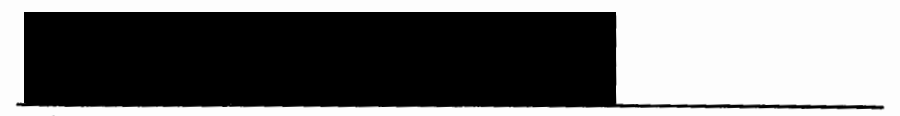

Charlene Clark

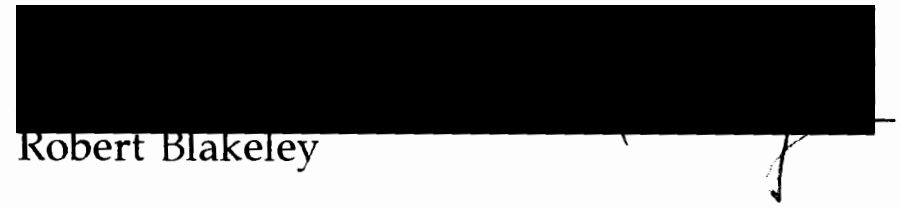

DEPARTMENT APPROVAL:

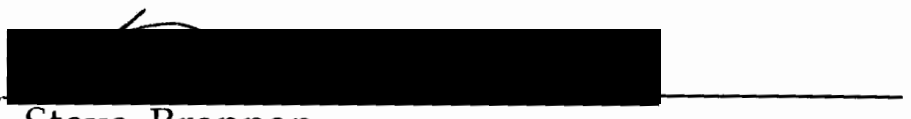

Steve Brannan

Representative of the Office of Graduate Studies

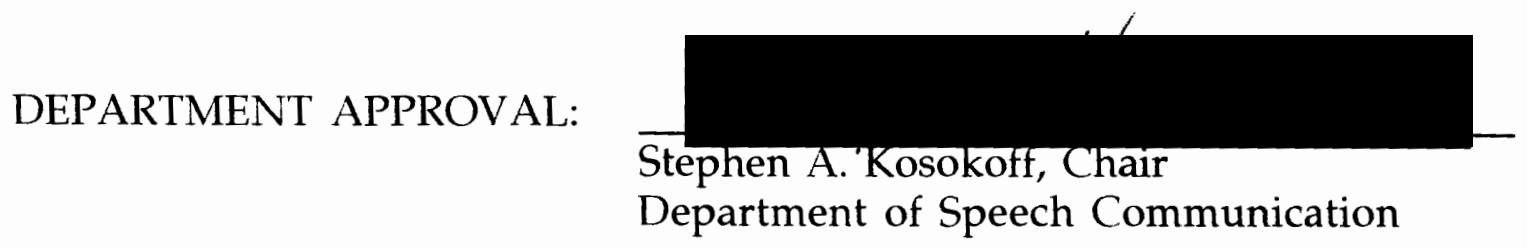

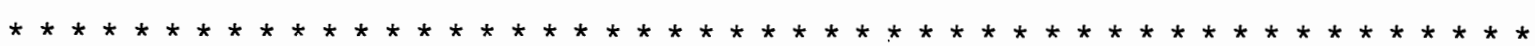

\section{ACCEPTED FOR PORTLAND STATE UNIVERSTTY BY THE LIBRARY}

by on

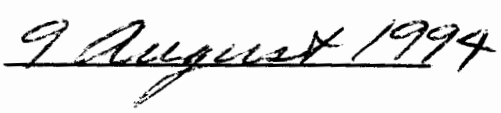




\begin{abstract}
An abstract of the thesis of Rosemary LeBlanc for the Master of Science in Speech Communication: Speech and Hearing Sciences presented July 13, 1994.
\end{abstract}

Title: The R-stick Appliance as a Device to Facilitate the Phoneme /r/.

One of the most common articulation errors made by children is on the phoneme $/ \mathrm{r} /$. Treatment techniques for this sound have varied and have included the stimulus approach (Van Riper, 1972), phonetic placement techniques (Scripture, 1923), the sensory-motor approach (McDonald, 1964), the motokinesthetics approach (Young \& Hawk, 1938), and sequential programming approach (Shriberg, 1975; Wood, 1988), to name a few. An integral part of many of these treatment methods is the use of the auditory stimulation.

An innovative technique using a prosthetic device to facilitate the production of $/ \mathrm{r} /$ was used by Leonti, Blakeley, and Louis (1975), in the treatment of a 9.8 year old male. A follow-up study was conducted by Clark, Schwarz, and Blakeley, (1993) in which a prosthetic device, the R-appliance, was used to facilitate the production of $/ \mathrm{r} /$ at the word level. The results of the study indicated that the appliance facilitated the production of $/ r /$ in isolation, in words, and in spontaneous speech. 
The present study investigated the use of the R-stick appliance as a facilitative device for the production of the $/ \mathrm{r} /$ phoneme at the word level. It was hypothesized that the experimental group (R-stick) would have higher mean scores at the word level than the control group (no R-stick). This hypothesis was not supported by the data. Both groups showed significant improvements in their $/ \mathrm{r} /$ word productions, but no difference was shown between the two treatment approaches.

There are several possible reasons for these results: (a) insufficient training with the use of the R-stick and the treatment protocol, (b) lack of probes during the course of the study, (c) length of treatment, (d) the small number of subjects participating in the study, and (e) the R-stick appliance is a clinician-manipulated tool. 
THE R-STICK APPLIANCE AS A DEVICE

TO FACILITATE THE PHONEME / r/

\author{
by \\ ROSEMARY LEBLANC
}

A thesis submitted in partial fulfillment of the requirements for the degree of

Master of Science in Speech Communication:

Speech and Hearing Sciences

Portland State University

1994 


\section{DEDICATION}

This piece of work is dedicated to my Dad, Leo J. and my sisters, Carol Ann and Janice Marie. May their spirits be remembered through the memories of family and friends. 


\section{ACKNOWLEDGMENTS}

I have many people to thank for where I am at this stage of my life. First, I want to thank my entire thesis committee, for without their ideas, input and insight, this project would never have been completed.

I want to especially thank Mary-Gordon Brannan, not just for her patience and immeasurable knowledge during the course of this study, but also for her support during my "school" years.

Thank-you Dr. Blakeley and Dr. Clark for your patience.

Thanks go to all the Portland Public school clinicians and their children for making this study possible. Thank you Rita Smith, Ellen Reuler, and Iva-Marie Connall for lending me an "ear" when I needed one.

This thesis is not a separate entity from my studies at Portland State University, therefore, I would like to acknowledge the support I received from Dr. Rhea Paul, Joan McMahon, Dr. Robert Casteel, Marie Hopple, and Mary T. Withers.

Last but not least, I want to thank my mother, Barbara and my dear friend, Rose, for putting up with my desperation calls at all hours of the day and night and for giving me that extra little push when I needed it. 


\section{TABLE OF CONTENTS}

PAGE

ACKNOWLEDGMENTS . . . . . . . . . . . . . . iii

LIST OF TABLES $\ldots \ldots \ldots \ldots \ldots \ldots \ldots \ldots \ldots \ldots$

CHAPTER

I INTRODUCTION AND STATEMENT OF PURPOSE . . 1

Introduction $\ldots \ldots \ldots \ldots \ldots \ldots \ldots$

Statement of Purpose $\ldots \ldots \ldots \ldots . \ldots 2$

II REVIEW OF THE LITERATURE . . . . . . . . . . 3

Articulation Development . . . . . . . . . 3

Intervention Placement Criteria . . . . . . . . . 4

Treatment Approaches of Articulation Disorders . 6

Elicitation of the Phoneme $/ \mathrm{r} / \ldots \ldots 7$

III METHODS ................... 10

General Plan of Study . . . . . . . . . . . . 12

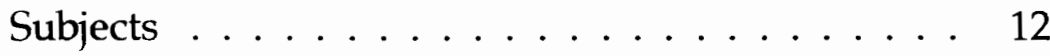


Instrumentation and Procedures . . . . . . 15

Pre- and Post-test Measures

Treatment Procedures

Reliability

Data Measurement and Analysis . . . . . . . 16

IV $\quad$ RESULTS AND DISCUSSION . . . . . . . . . . 18

Results. . . . . . . . . . . . . . 18

Discussion. . . . . . . . . . . . . 21

$\mathrm{V} \quad$ SUMMARY AND IMPLICATIONS . . . . . . . . . 25

Summary . . . . . . . . . . . . . 25

Implications . . . . . . . . . . . . 26 26

Research

Clinical

REFERENCES . . . . . . . . . . . . . . . . . . 28

APPENDIXES

A Letter to Parents/Permission Slip . . . . . . . . 31

B Auditory Discrimination Test . . . . . . . . 35

C Picture of R-stick Appliance . . . . . . . . . 37

D $\quad / \mathrm{r} /$ Pretest-Posttest List . . . . . . . . . . 39

E Protocol for Appliance Placement . . . . . . . . . 41 


\section{LIST OF TABLES}

TABLE

PAGE

1 Summary of Subjects by Age, Gender, and Group

Assigned . . . . . . . . . . . . . . . . 13

2 Summary of Individual Pretest and Posttest Raw Scores, Percentage Correct out of 60 Words, and the Difference Between the Pretest and Posttest . . . . . . . . . . . . 19

3 Summary of Group Mean (M), Standard Deviation (SD), and Range of Raw Scores . . . . . . . . . . . . . 20

$4 \quad$ Rank Order of Percentage of Correct Production in Word Categories for Pretest and Posttest . . . . . . . . . . . . 21 


\section{CHAPTER I}

\section{INTRODUCTION AND STATEMENT OF PURPOSE Introduction}

One of the most common articulation errors made by children is on the phoneme $/ \mathrm{r} /$. The sound is not only difficult to produce (Kenny \& Prather, 1986), but is one of the most difficult to correct (Weiss, Gordon, \& Lillywhite, 1987). Intervention techniques have varied; however, the most frequently used has been the traditional intervention mode of auditory input. According to Weiss et al. (1987), the contour, width, and movement of the tongue are extremely important and necessary for the correct production of $/ \mathrm{r} /$. However, when producing $/ \mathrm{r} /$, the tongue is not visible and children may alter their tongue position yet continue to produce the sound according to their internal perceptual model of the phoneme (Monnin, 1984), which becomes a complicating factor for teaching children to produce this sound. Therefore, treatment of $/ \mathrm{r} /$ often continues for extended periods of time with little or no improvement.

A promising approach for teaching children to produce the phoneme /r/ was recently reported. In a 1993 study, Clark, Schwarz, and Blakeley investigated the use of a prosthetic device, the R-appliance, in facilitating the production of $/ \mathrm{r} /$. Two of the four groups in their study received articulation treatment utilizing the R-appliance. They reported that 16 of 18 subjects correctly produced the $/ \mathrm{r} /$ phoneme in a remarkably short period of time. The R-appliance was fitted by a dentist and placed in the maxillary arch of a subject and secured in place by four ball clasps. More recently a prototype appliance, the R-stick appliance, has been developed. This appliance is an acrylic mound without ball clasps. The R-stick appliance eliminates the need for clasp adjustment and personalized fitting. It is hypothesized that the R- 
stick appliance will be as effective as the R-appliance in facilitating the production of the / $\mathrm{r} /$ without the need for personalized fitting.

\section{Statement of Purpose}

The purpose of this study was to compare the effect of a prosthetic device, the R-stick appliance, placed in the maxillary arch, in facilitating the production of / $\mathrm{r} /$ with an approach not using the R-stick appliance. The research question for this investigation was: Will the use of the R-stick appliance facilitate the correct production of $/ \mathrm{r} /$ at the word level in schoolaged students? This question was addressed by comparing the results of articulation treatment for / r/ delivered to two groups of school-aged children, with one group receiving treatment with the R-stick appliance and the control group receiving treatment without the R-stick. The research hypothesis tested was: the appliance group will show greater improvement in $/ \mathrm{r} /$ production in words than the non-appliance group. 


\section{CHAPTER II \\ REVIEW OF THE LITERATURE \\ Articulation Development}

Several studies have been conducted regarding age levels for speech sound acquisition. The focus of this review will be the acquisition of the phoneme $/ \mathbf{r} /$. In a relatively recent study of articulation development in children, Prather, Hedreck, and Kern (1975) reported findings similar to other studies on sequence of articulation development. They tested 147 children, aged 2:9-4:0, and compared their results to data collected by Templin (1957), and Wellman, Case, Mengert, and Bradbury (1931). Although sequence similarities were found in these three classic studies, the Prather et al. (1975) data suggested that sounds were generally produced correctly at younger ages than the earlier studies showed.

Discrepancies in the age level for acquisition of $/ \mathrm{r} /$ were noted among the three studies. As tested in two positions, initial and final, Prather et al. (1975) reported / $\mathrm{r} /$ to be correctly produced at age $3: 4$ by $75 \%$ of the children evaluated. However, when using the $75 \%$ criterion for correct production in all three positions, initial, medial, and final, as opposed to a less stringent standard of two positions used by Prather et al., the age of correct production was higher in Templin's (1957) study and in the Wellman et al. (1931) study, with the ages of acquisition being 4:0 and 5:0 respectively. Another study on phoneme acquisition of children ages 3:0-6:0 was conducted by Arlt and Goodban (1976). Their findings for the phoneme / r/ using the criterion of $75 \%$ correct sound production in all three positions resulted in findings similar to Wellman et al. (1931), that is, at the later age of 5:0. 
The discrepancy in the age of acquisition of $/ \mathrm{r} /$ may be due to the criteria used to specify when a sound is "learned," that is, of two versus three positions tested or to the percentage of children who must demonstrate correct production. In the most recently reported study on sound acquisition, Smit, Hand, Freilinger, Bernthal, and Bird (1990) tested 947 children, ages 3:09:0. The criterion for considering a sound to be acquired was $90 \%$ accuracy in three positions. Using this more rigorous criterion, the phoneme $/ r /$ was placed at an 8:0 age level. However, when using the $75 \%$ criteria, the age of acquisition was 6:0 for males and 5:6 for females, older age levels than shown by earlier acquisition studies.

Sander (1972) rejected the notion of assigning a particular developmental age level to a sound; rather he recommended the use of the criterion of customary production versus mastery of a sound. Customary production, as defined by Sander, is the age level when a sound is articulated clearly by $51 \%$ or more of children in at least two of three positions. Sander recommended that a table specifying an average age of production and the traditional upper age limits be used to account for the variability in the development of articulation. Using data collected by Wellman et al. (1931), Templin (1957), and Smit et al. (1990), acquisition of the / r/ would have a developmental age range of 3:0-9:0, with a customary production or average age of 6:0. It is from these normative data that articulation caseloads are selected.

\section{Intervention Placement Criteria}

Stewart and Weybright (1980) investigated how caseloads were selected in the State of Oregon. They sent questionnaires to 263 speech-language 
pathologists and asked them which norms they used when assessing articulation development when determining caseloads. Of the 145 questionnaires returned, 51\% used Templin's 1957 norms, 18\% used Poole's 1934 norms, and 9\% used the 1975 norms of Prather et al. The rest of the respondents (21\%) used various combinations of these norms. It was further reported that $23(6 \%)$ clinicians based their assessment, and subsequent determination of service, on related factors such as speech intelligibility, overall development of the child, and error sound stimulability.

These norms would place children in intervention programs for $/ \mathrm{r} /$, by the majority of the clinicians sampled, at the age of 4 years. However, this is not necessarily the case. For example, the guidelines for the Portland Public School clinicians in Portland, Oregon specify three criteria that children must meet prior to intervention for articulation errors: "(a) the child must be a minimum of 7 years of age, (b) the problem must interfere with communication, and (c) the error must call attention to itself" (Portland Public Schools, 1986, pp. 42, 42a). Furthermore, intervention is often denied to children with residual articulation errors because the error is not judged to be an interfering factor with the educational process (Silverman \& Paulus, 1989). Children are considered to have a residual articulation disorder if they continue to produce distortion errors by school-age (Shriberg, Kwiatkowski, Best, Hengst, \& Terselic-Weber, 1986). Therefore, a child may not receive services for a residual articulation disorder, with the most common errors involving the production of $/ \mathrm{s} /, / \mathrm{r} /$, and $/ 1 /$, until the age of 7 or 8 when Sander (1972) reported that $90 \%$ of children have mastered the sound system of English. 
Due to the current national emphasis to serve moderately and severely impaired children, there has been a $20 \%$ decline in the number of children with speech impairments (includes speech and language disorders) receiving services since 1978-79 (Neidecker, 1987). A recent trend in schools shows that the percentage of articulation disorders in caseloads is decreasing, that is, $47 \%$ of caseloads as reported by Dublinski (1981) in contrast to 66\% in 1976 (Neal, 1976). This is a 19\% decline in treatment of articulation disorders in only 5 years. However, articulation disorders persist into adulthood as indicated by the results of Culton's (1986) study, in which 30,586 college freshman students were screened for speech and language disorders over a 13-year period.

Culton found that articulation disorders continued to be the most common speech problem, occurring in $1.37 \%$ of the people screened. It was further reported that only $10.7 \%$ of the students with articulation errors recovered without intervention, and only $46 \%$, following speech intervention, recovered by the time they entered college.

\section{Treatment Approaches of Articulation Disorders}

Many approaches to the treatment of articulation disorders are available. One of the more traditional approaches, the stimulus approach, was developed by Van Riper (1972). The basic goals are: (a) recognition of the error, (b) auditory stimulation, (c) mastery of the isolated sound, (d) use of the sound in a syllable, (e) use of the sound in a word, (f) use of the sound in a phrase or sentence, and (g) transfer and maintenance into all contexts and environments. Van Riper (1972) identified five methods for eliciting speech sounds: (a) progressive approximation, (b) auditory stimulation, (c) phonetic placement, (d) modification of other sounds, and (e) key word. Phonetic placement techniques were originally devised by Scripture (1923, in 
Scripture, 1975). who also emphasized tongue and lip exercises, breathing, and relaxation which Van Riper did not.

Another treatment approach for articulation disorders is McDonald's (1964) sensory-motor approach that facilitates the correct articulation of an error sound in systematically varied phonetic contexts through the use of auditory, proprioceptive, and tactile sensations of articulatory movements. A third approach, motokinesthetics, has been developed and involves direct stimulation and manipulation of the speech musculature by the speechlanguage pathologist (Young \& Hawk, 1938). Direct manipulation of the mouth, jaw, and neck regions is performed externally. Speech sounds are elicited in the context of words with auditory, visual, and tactile sensory inputs; thus, auditory stimulation is an integral part of motokinesthetics as it is with the other two approaches mentioned thus far.

Other approaches to the treatment of articulation disorders are described in the literature, most of which are more appropriate for multiple articulation errors. They will not be presented here since the focus of this study involved the misarticulation of only one phoneme, $/ \mathrm{r} /$.

Elicitation of the Phoneme / $/$ /

Several techniques for elicitation of $/ \mathrm{r} /$ have been described in the literature. One such technique is the response evocation program for children who have developmental errors on / r/ and / 3 / (Shriberg, 1975). Three components of the program are specified: (a) exact instructions to be given by the clinician, (b) a response definition, and (c) termination criteria. The program is presented in an eight-step systematic sequence. Shriberg found the mean time for a child to progress through the program was 6 
minutes and concluded that the program enhanced the clinician's effectiveness in evoking the 134 .

As a follow-up, Shriberg (1980) reported informal data collected from clinicians that showed the response evocation program elicited acceptable $/ \mathrm{r} / \mathrm{s}$ from most of their subjects, but was not successful with those who had persistent $/ \mathrm{r} /$ errors. He presented a diagnostic teaching procedure of an eight-step process to be used with children who had persistent $/ \mathrm{r} /$ errors. Three steps are done in the assessment phase and five steps are completed in the diagnostic teaching phase. The basic premise of the procedure is to "extinguish all exaggerated articulatory gestures accompanying attempts at acceptable $/ \mathrm{r} /$ productions while facilitating the child's awareness of correct tongue shape and tongue movement for /r/" (Shriberg, 1980, p. 105).

Step 1 of the diagnostic teaching phase requires the child to imitate sounds such as consonant-vowel and vowel-consonant syllables. Step 2 involves assisting the child in recognizing the difference between relaxed natural gestures made on error sounds versus non relaxed natural gestures. In step 3, a bite stick is introduced to aid in stabilizing the jaw thus allowing the tongue to move independently of jaw movements. Step 4 is a continuation of step 3 with the child now controlling the bite stick and saying some stop-vowel and nasal-vowel combinations. In step 5, the child continues to practice without direction from the clinician as to tongue and lip placement. It was noted that a fading procedure was used to eliminate the use of the bite stick gradually. Once the $/ \mathrm{r} /$ is stabilized, the more traditional approach of syllable to word, phrase, sentence, cued speech, and spontaneous speech is implemented. No data regarding the efficiency and effectiveness of this program were reported (Shriberg, 1980). 
Another clinical technique for elicitation of the 154 was presented by Wood (1988). This technique entails the movement from the vowel /i/ to elicit $/ 34$. The clinician guides the child through an eight-step process that utilizes the key element of this technique, that is, lingual tension. The goal of the program is to attain correct production of 154 and to eliminate the necessity of /i/ as a production tool. Although no data were provided, Wood reported this technique to be successful with elementary school children 8 years of age and older.

The use of a prosthetic device to assist in the production of $/ \mathrm{r} /$ was presented by Leonti, Blakeley, and Louis (1975). A device, the R-appliance, was used with a 9.8 year old male child who continued to misarticulate $/ \mathrm{r} /$ after receiving traditional treatment. In a later study, Clark et al. (1993) investigated the use of the R-appliance as a device for facilitation of $/ r /$. The R-appliance, as described by Clark et al., is a removable appliance which is similar in design to the palatal portion of an orthodontic retainer. Their study included 36 subjects, ages 8 to 12 years, who had received traditional articulation intervention for the $/ \mathrm{r} /$ for a minimum of 6 months and had failed to make any significant progress. Results of this study indicated that the appliance facilitated the production of $/ \mathrm{r} /$ in isolation, in words, and in spontaneous speech. The study also showed the R-appliance is a plausible non-invasive alternative treatment method that can be used in a clinical setting.

Exactly how the R-appliance works was not within the realm of the Clark et al. study. However, they reported the appliance facilitates changing the resonance of the oral cavity rather than changing tongue positions, because the correct sound can be produced when using various tongue 
postures. Once the appliance is in place, there is a modification of resonance in the oral cavity, thus through vocal play, tongue posturing, and auditory feedback, the subject can achieve the correct production of $/ \mathrm{r} /$. One element that remained constant in correct $/ \mathrm{r} /$ production appeared to be the contact of the lateral borders of the tongue against the lingual surfaces of the posterior teeth. Clark et al. (1993) reported 16 of 18 subjects who received the appliance produced the target phoneme within the initial 45-minute appliance placement visit. It appears evident that the $\mathrm{R}$-appliance is a viable approach to treatment of $/ \mathrm{r} /$ as it was used successfully in a variety of settings by 14 clinicians with 18 grade school children.

Although effective, one problem encountered with the R-appliance was the clasps breaking due to the handling of the appliance. Although this problem occurred infrequently, it was time-consuming to fix the appliance. An alternative prosthetic device, the R-stick appliance, does not have to be clasped to the subject's teeth and can be removed more quickly and easily. Another problem reported was that two subjects in the Clark et al. study reported difficulty swallowing when the R-appliance was in place and wanted it removed when they needed to swallow. The R-stick appliance may not alleviate the need to swallow; however, since it is easily removable, valuable treatment time could be saved.

In summary, it seems that $/ \mathrm{r} /$ is a sound that continues to be misarticulated after many of the other speech sounds have developed. Treatment approaches for this sound vary and have included the stimulus approach (Van Riper, 1972), phonetic placement techniques (Scripture, 1975), sensory-motor approach (McDonald, 1964), motokinesthetics approach (Young \& Hawk, 1938), and sequentially programmed approach (Shriberg, 
1975; Wood, 1988), to name a few. Many of these approaches use auditory stimulation as an integral part of the treatment. It is hypothesized that the Rappliance and its prototype, the R-stick appliance, modifies oral cavity resonance, such that, when $/ r /$ is correctly produced, the client receives correct auditory feedback. It is thus postulated, that by using the R-stick appliance with a treatment protocol, that does not include an auditory stimulus, the subjects will improve their production of the $/ r /$ at the word level, as the appliance will create an environment for the correct sound to be produced and heard. 


\section{CHAPTER III \\ METHODS \\ Plan of Study}

This study utilized a group design to investigate the effects of the Rstick appliance on the facilitation of production of $/ r /$ in isolation and in words. The school-aged subjects misarticulated the $/ \mathrm{r} /$ sound and had received speech intervention for their $/ \mathrm{r} /$ misarticulations. The subjects were divided into two groups and received 8 weeks of articulation treatment for $/ \mathrm{r} /$. One group received articulation treatment incorporating the R-stick appliance and a matched group was in a treatment program that did not use the R-stick.

\section{Subjects}

Sixteen children were recruited from Portland Public School District, Portland, Oregon, to serve as subjects for this investigation. Four subjects did not complete the study due to unforeseen circumstances. Originally, the subjects were divided into two groups of equal size and matched as closely as possible for chronological age. Twelve subjects (8 males, 4 females), ranging in age from 8 to 14 years, completed the study. The experimental group (R-stick appliance) was comprised of 7 subjects, 5 males (mean age of 10.6), and 2 females (mean age of 10.5). The control group (non-appliance treatment group) was comprised of 5 subjects, 3 males (mean age of 10.6), and 2 females (mean age of 10.5). (See Table 1).

All subjects met the following criteria:

1. Signed consent form for participation in the study (Appendix A).

2. Chronological age of 8-17 years. 
Table 1

Summary of Subjects by Age, Gender, and Group Assigned

\begin{tabular}{rrrl}
\hline & Age & Gender & Group \\
\cline { 2 - 4 } Subject & & & \\
& & & \\
1 & 8 & M & Control \\
3 & 9 & F & (no stick) \\
2 & 10 & M & \\
4 & 12 & F & \\
5 & 14 & M & \\
12 & & & \\
10 & 8 & M & Experimental \\
9 & 10 & M & \\
7 & 11 & F & \\
11 & 11 & M & \\
6 & 12 & M & \\
8 & 12 & M & \\
& 14 & F & \\
\hline
\end{tabular}

Note. The average age was 10.6 for the control group and 11.1 for the experimental group. 
3. Normal intelligence as reported by referring speech-language clinician.

4. Normal language development as reported by referring speechlanguage clinician.

5. Hearing within the normal range as reported in school hearing screening information.

6. Residual articulation error on $/ \mathrm{r} /$ with no known neurological deficit.

7. Minimum of 6 months of remediation in which the phoneme $/ \mathrm{r} /$ was targeted, but in which no significant gain was made.

8. Ability to discriminate $/ \mathrm{w} /$ from $/ \mathrm{r} /$.

9. Native English speaker with English spoken in the home.

10. Not wearing orthodontic appliance that would interfere with the R-stick appliance.

The subjects in this study showed the ability to discriminate correctly $80 \%$ of the items given on a non-standardized auditory discrimination test of w-r continuum developed by Clark (1989) (Appendix B). The subjects selected also had a $75 \%$ or more combined $/ \mathrm{r} /$ and $/ 5 /$ error production rate on three production screening measures: (a) a 3-minute structured language sample, (b) the Goldman-Fristoe Test of Articulation (Goldman \& Fristoe, 1976), and (c) a Deep Test of Articulation for / $/ \mathrm{r}$ and / $/$ / (McDonald, 1964).

\section{Instrumentation and Procedures}

The R-stick appliance was used with the experimental group. The Rstick consists of an acrylic palate placed on the end of stick and is made to fit different size palates (Appendix $C$ ). The six clinicians who participated in the 
study received training, prior to the study, in the use of the R-stick appliance. The clinicians received the same instructions and were given the same information prior to the initiation of treatment. The training consisted of viewing a 45-minute audio/videotape, developed by Blakeley and Clark (1992), in which Blakeley explained and demonstrated how the R-stick appliance is used.

\section{$\underline{\text { Pre- and Post-test Measures }}$}

The clinicians administered pretest measures to the subjects. The pretest included $60 / \mathrm{r} /, / 34$, and $/ \$ 1$ words in the following six categories:

1. words with the target sound in initial position.

2. words with the target sound in medial position.

3. words with the target sound in final position.

4. words containing r-blends.

5. words containing stressed $|\$|$.

6. words containing unstressed $/ 27$ (Appendix D). After completion of the $/ \mathrm{r} /$ articulation treatment, posttesting was conducted using the same items as used in the pretest.

The pre- and post-test items for all subjects were audiotaped, using personal cassette players, by the assigned clinicians at their schools. The scorer who judged the tapes is a certified speech-language pathologist, currently practicing in the field.

\section{Treatment Procedures}

The treatment protocols were carried out by certified speech-language pathologists in the public schools. The treatment protocol for the experimental group (R-stick) is shown in Appendix E. The control group 
received traditional (i.e., stimulus approach, phonetic placement) treatment only, and the experimental group received the R-stick appliance treatment in conjunction with the treatment protocol. Each subject was seen individually for 30 minutes, twice weekly, for a period of 8 weeks. The clinicians were provided with an individual packet of material for each subject, depending on the protocol to which the subject was assigned. The packets contained blank audio tapes, suggested word lists, and a list of pre- and post-test words. The clinicians in the control group (no-stick) were not given a treatment protocol, but were requested to continue with their current treatment technique for the $/ \mathrm{r} /$ sound.

$\underline{\text { Reliability }}$

To achieve reliability, two judges listened to a training audiotape developed by Clark (1989) that contained 60 words in which the $/ \mathrm{r} /$ phoneme occurred in the initial, medial, final, stressed, and unstressed positions of words (10 in each position). Both judges were currently practicing certified speech-language pathologists. The two judges evaluated the $/ \mathrm{r} /$ production to be correctly or incorrectly produced and their judgments were compared. They achieved $85 \%$ point-to-point agreement on the last 20 words they assessed from the training tape. The two judges then listened individually to the pretest and posttest $/ \mathrm{r} /$ productions of three randomly selected subjects in this study. The percentage of agreement between the judges for the pre- and post-test $/ \mathrm{r} /$ productions for these three subjects ranged from $88 \%$ to $97 \%$, with an overall point-to-point agreement of $92 \%$. One of the judges participated as the scorer for this study and evaluated all the pre- and posttest /r/ productions. 
Data Measurement and Analysis

The percentage of correct $/ \mathrm{r} /$ production in words, prior to treatment and following treatment, was determined for each subject. The difference between the scores of the two groups was compared using a one-way analysis of covariance (ANCOVA) in order to ascertain if there was a significant difference between the two treatment groups on r-word productions. ANCOVA was used to account for the pre-test score differences between the two groups. The level of statistical significance was set at .05 . 


\section{CHAPTER IV \\ RESULTS AND DISCUSSION \\ Results}

The purpose of this study was to investigate whether the R-stick appliance would facilitate the production of the $/ \mathrm{r} /$ phoneme at the word level. The original design of the study included 16 subjects who were divided into two groups of equal size and matched as closely as possible for chronological age. However, only 12 of the 16 subjects completed the 8-week treatment study, which left 7 subjects in the experimental group (R-stick), and 5 subjects in the control group (no R-stick).

The results following 8 weeks of intervention show that the mean score for the control group for the production of 60 words in which the $/ \mathrm{r} /$ phoneme occurred in the initial, medial, final, stressed, and unstressed positions of words (10 in each position) was slightly higher than those of the experimental group. A summary of the pretest and posttest raw scores, with percentage correct and the difference between the pretest and posttest scores for the two groups, is presented in Table 2 . As can be seen, gains were made in both groups. The control group scores increased from a pretest mean score of 14.8 to 34.2 , for a total of 19.4 points; and the appliance group scores increased from a pretest mean of 20.0 to 32.6 for a gain of 12.5 points as shown in Table 3.

The raw score data were subjected to an ANCOVA. The ANCOVA analysis was used to equate the groups in terms of their pretest performance, and the posttest score was thus adjusted to account for the difference between the pretest scores of the two groups. The adjusted mean score for the control group was 37.5 and for the experimental group was 30.2. The findings show 
Table 2

Summary of Individual Pretest and Posttest Raw Scores, Percentage Correct out of 60 words, and the Difference between the Pretest and Posttest

\begin{tabular}{|c|c|c|c|c|c|c|}
\hline & \multirow[t]{2}{*}{ Group } & \multicolumn{2}{|c|}{ Pretest } & \multicolumn{2}{|l|}{ Posttest } & \multirow{2}{*}{$\begin{array}{l}\text { Difference } \\
\text { Raw Score }\end{array}$} \\
\hline & & Raw Score & $\%$ & Raw Score & $\%$ & \\
\hline \multicolumn{7}{|c|}{ Subject } \\
\hline 1 & control & 14 & 23 & 34 & 57 & +20 \\
\hline 2 & (no stick) & 20 & 33 & 34 & 57 & +14 \\
\hline 3 & & 5 & 8 & 21 & 34 & +16 \\
\hline 4 & & 18 & 30 & 25 & 42 & +7 \\
\hline 5 & & 17 & 28 & 57 & 95 & +40 \\
\hline 6 & experimental & 3 & 5 & 21 & 34 & +18 \\
\hline 7 & (stick) & 30 & 50 & 38 & 63 & +8 \\
\hline 8 & & 37 & 62 & 55 & 92 & +18 \\
\hline 9 & & 1 & 2 & 7 & 12 & +6 \\
\hline 10 & & 36 & 60 & 42 & 70 & +6 \\
\hline 11 & & 30 & 50 & 53 & 88 & +23 \\
\hline 12 & & 3 & 5 & 12 & 20 & +9 \\
\hline
\end{tabular}


Table 3

Summary of Group Mean (M), Standard Deviation (SD), and Range of Raw $\underline{\text { Scores }}$

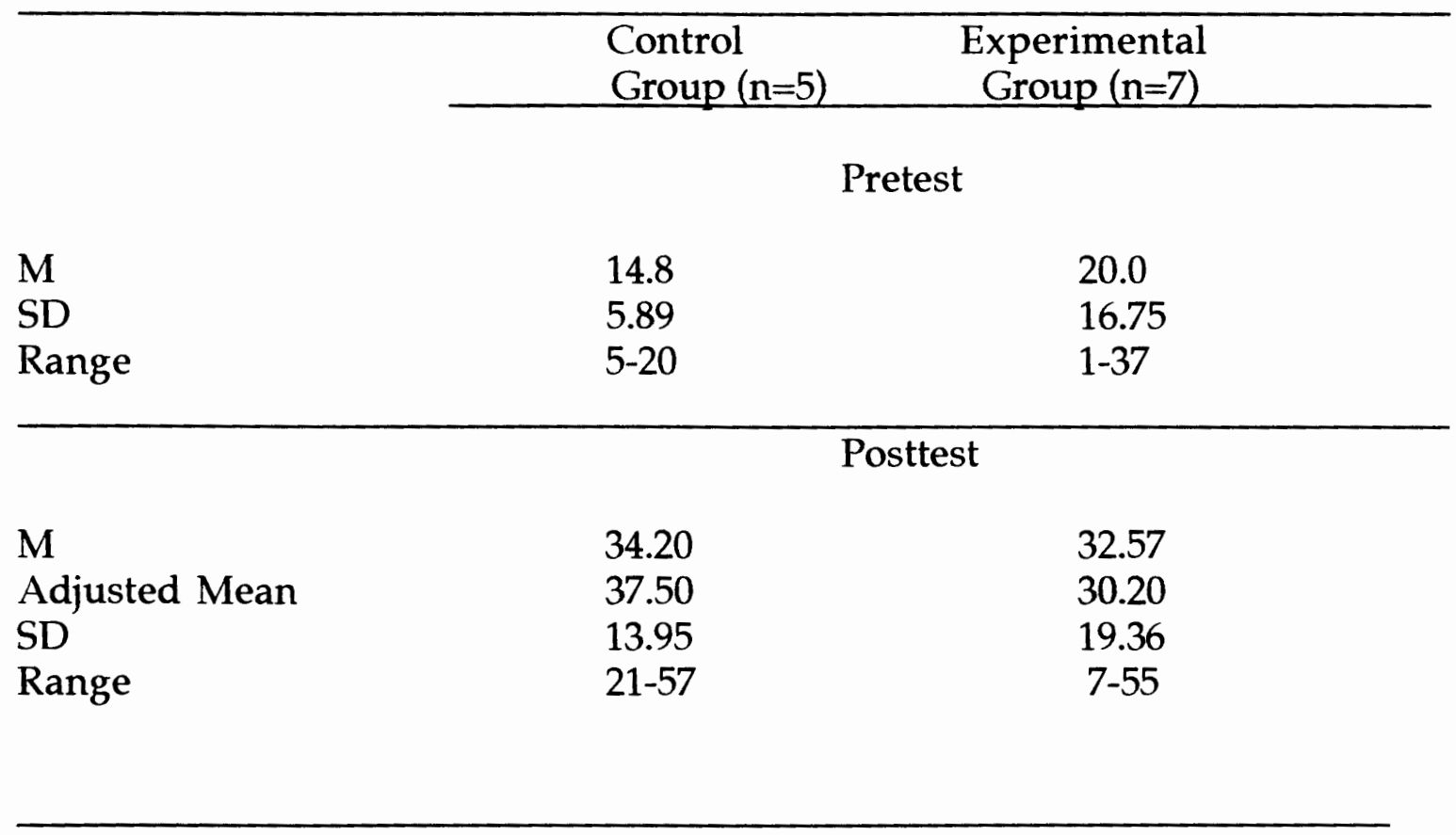

the effect between the control group and the experimental group was not significant $(\underline{F}(1,9)=1.48, \underline{p}=.255)$. The ANCOVA did show a significant effect between the pretest and posttest scores. Thus, both treatment groups ( $R$ stick and no R-stick) improved their production of / $\mathrm{r} /$ in words, but neither treatment approach was found to be better than the other for these subjects.

The percentage of correct productions, per category for the 60 words, for the posttest, ranged from $5-14 \%$ for the control group and $6-12 \%$ for the experimental group. The greatest percentage of correct productions for both groups was $/ \mathrm{r} /$ in the medial position of words. The second largest gain for 
both groups was in the $/ \mathrm{r} /$ - blend category. The rank ordering of $/ \mathrm{r} /$ by percentage of correct productions in other positions varied. (Table 4).

Table 4

Rank Order of Percentage of Correct Productions in Word Categories for Pretest and Posttest

\section{Rank Order}

Control (no stick) Experimental (stick)

Word Category

pretest posttest pretest posttest

Initial

Medial

Final

Blends

Stressed

Unstressed
3

1

4

2

6

5
3

1

6

2

5

4
6

1

3

5

4

2
4

1

3

2

6

5

\section{Discussion}

It was anticipated that the results of this study would show a significant difference between the experimental group and the control group for an increased correct production of $/ \mathrm{r} /$ at the word level. However, there was not a significant difference between the groups. Several possible reasons are postulated for these findings.

First, the training of the clinicians in using the R-stick and the treatment protocol appears to have been inadequate. After completion of the study, all of the participating clinicians stated that they could have used more training in both the use of the R-stick, as well as the protocol. The training video, although helpful, did not address the use of the protocol that would be 
used during the course of the study. It is also noted that the researcher did not have first-hand experience with the protocol or the R-stick appliance.

Second, no probes were conducted during the course of the study. In the Clark et al. (1993) study, two 30-word probes were administered by the researcher to all participating subjects. The data collected were used to note progress at the second and fourth week of the study. It was reported that in both probes the two groups receiving treatment with the $\mathrm{R}$-appliance made greater gains than the other 2 treatment groups. Progress of the subjects was not monitored during the course of treatment in this study. The probing procedure also provided an opportunity for the clinician and researcher to problem-solve if necessary. In this study, the clinicians did not have the opportunity to address any questions they may have had.

Third, the treatment period may have been too long to find a difference between the two approaches. It is possible that the two groups progressed at different rates. Perhaps the stick group or the no-stick group outperformed the other group earlier in the course of the 8-week treatment. These results do not provide information about which approach is most efficacious. In the Clark, et al. (1993) study, the treatment lasted only 6 weeks and the appliance groups improved significantly more than the non-appliance groups. It could be that a difference between the two groups in this study would have been found with a shorter period of treatment.

Fourth, there may not have been enough subjects in this study to show group differences. One or two subjects may overly influence the results in a group design such as this. The Clark et al. (1993) study involved 36 subjects. The subjects for this study were recruited from Portland, Oregon public schools. Six clinicians volunteered to participate resulting in 16 subjects. 
However, only 12 subjects completed the course of the study. This may be due, in part to the current emphasis on serving moderately and severely impaired children (Neidecker, 1987). Also, a few clinicians who did not participate stated that, with their caseload size and time constraints, they could not work one-on-one with an individual. However, it is noted that all the subjects in this study showed significant improvement with intervention that was based on a one-to-one model, two times weekly. Perhaps this delivery model influenced the results more than the two specific treatment approaches used.

Finally, the R-stick appliance is subject to more variability in its placement in the oral cavity than the R-appliance as the R-appliance is fitted to a child's mouth and held in place by four ball clasps (Clark et al., 1993). The $\mathrm{R}$-stick appliance is a clinician-manipulated tool. The clinician, during the course of the study, was required to manipulate the R-stick to obtain the required sound. Therefore, the target sound may have varied from production to production if the appliance was not placed consistently. The clinicians indicated that it was difficult to manipulate the R-stick and follow the treatment protocol at the same time. This problem may be alleviated with more extensive training and time spent with the R-stick appliance.

Clark (1989) reported that there is some disagreement in the literature as to the role of stress in the production of $/ \mathrm{r} /$. In the current study, the greatest percentage of correct productions for both pretest and posttest were made in the medial positions of words. These findings were consistent with Clark's (1989) study. However, in her study, it was found that the fewest correct productions were made for the stressed 137 (e.g., bird, girl), in both the pretest and posttest assessments. That was not the case in this study as the 
rank order for the fewest correct productions varied in both the pretest and the posttest. It was further noted that the overall rank order of production varied more from pretest to posttest for the experimental group (R-stick) than for the control group (no-stick).

Findings of the present study are further discussed in Chapter V, in terms of implications of this study. In addition, suggestions for further research are given. 


\section{CHAPTER V \\ SUMMARY AND IMPLICATIONS \\ Summary}

One of the most common articulation errors made by children is on the phoneme $/ \mathrm{r} /$. Treatment techniques for this sound have varied and have included the stimulus approach (Van Riper, 1972), phonetic placement techniques (Scripture, 1975), the sensory-motor approach (McDonald, 1964), the motokinesthetics approach (Young \& Hawk, 1938), and sequential programming approach (Shriberg, 1975; Wood, 1988), to name a few. An integral part of many of these treatment methods is the use of auditory stimulation.

An innovative technique using a prosthetic device to facilitate the production of $/ \mathrm{r} /$ was used by Leonti et al. (1975), in the treatment of a 9.8 year old male. A follow-up study was conducted by Clark et al. (1993) in which a prosthetic device, the R-appliance, was used to facilitate the production of $/ \mathrm{r} /$ at the word level. The results of the study indicated that the appliance facilitated the production of $/ \mathrm{r} /$ in isolation, in words, and in spontaneous speech.

The present study investigated the use of the R-stick appliance as a facilitative device for the production of the $/ \mathrm{r} /$ phoneme at the word level. It was hypothesized that the experimental group (R-stick) would have higher mean scores at the word level than the control group (no R-stick). This hypothesis was not supported by the data. Both groups showed significant improvements in their $/ \mathrm{r} /$ word productions, but no difference was shown between the two treatment approaches. 
There are several possible reasons for these results: (a) insufficient training with the use of the R-stick and the treatment protocol, (b) lack of probes during the course of the study, (c) length of treatment, (d) the small number of subjects participating in the study, and (e) the R-stick appliance is a clinician-manipulated tool.

\section{Implications}

\section{$\underline{\text { Research }}$}

Because of the findings of Clark et al. (1993) study in which the Rappliance was shown to facilitate the production of $/ \mathrm{r} /$, further research on the R-stick appliance seems warranted. Several factors could be changed from the design of this study that may affect the outcome in future research. One of the main factors would be to increase the amount of clinician training with the use of the R-stick appliance, as well as with the treatment protocol, prior to the study. The training could include actual practice with the R-stick appliance, introduction to the treatment protocol, and viewing of the training video.

To provide more control, the clinicians could be monitored during the course of treatment to provide them with feedback. Also, by conducting probes at two-week intervals, treatment efficacy could be more effectively investigated because one could ascertain when changes occurred. Another possibility would be to conduct the study with a larger number of subjects, with the opportunity of using the R-stick appliance with and without the treatment protocol. A final possibility would be to conduct the study with younger children. The average age was 10.6 for the control group and 11.1 for the experimental group. The youngest subject in this study was 8 years of age. It would be interesting to see if the R-stick appliance would facilitate 
production of the $/ \mathrm{r} /$ sound before it becomes embedded, or before the internal perceptual model is stored incorrectly (Monnin, 1984).

\section{Clinical}

The data collected from this research did not support the hypothesis that the R-stick appliance resulted in greater mean scores for correct $/ r /$ word production than the non-appliance group. However, there was a significant improvement for both groups from pretest to posttest. This is an indication that intervention was effective. It is also noted that these children normally would have received treatment in a group setting; however, the study afforded the opportunity for the children to receive one-on-one treatment, twice weekly, with a speech-language pathologist. A research study to investigate group versus one-on-one treatment may show which model of intervention is more effective.

The R-appliance is considered to be a useful clinical tool in facilitating the production of $/ r /$. The Clark et al. (1993) study reported statistically significant differences in favor of the groups who used the R-appliance. It was further reported that 13 out of 14 clinicians felt that the R-appliance was time effective in teaching the client posture for producing the $/ \mathrm{r} /$ phoneme.

The prototype R-stick appliance is a tool that has tremendous potential for success in the treatment of the sound $/ \mathrm{r} /$. It has the advantage over the $\mathrm{R}$-appliance of not requiring a dentist or pedodontist to make and fit the appliance. The R-stick appliance is an easily manipulated tool, however, training with the tool, prior to application, appears to be a necessity for clinical success. 
References

Arlt, P., \& Goodban, M. (1976). A phonetic study of misarticulation acquisition as based on a study of 240 normals, aged three to six. Language, Speech and Hearing Services in the Schools, Z, 173-180. Blakeley, R. (speaker), \& Clark, C. (speaker). (1992). R-stick training tape [videotape]. Undistributed.

Clark, C. (1989). The removable R-appliance as a practice device to facilitate the correct production of the phoneme $/ \mathrm{r} /$. Unpublished doctoral dissertation, University of Oregon, Oregon.

Clark, C., Schwarz, I., \& Blakeley, R. (1993). The removable R-appliance as a practice device to facilitate the correct production of $/ \mathrm{r} /$. American Lournal of Speech-Language Pathology, 2, 84-92.

Culton, G. (1986). Speech disorders among college freshmen: A 13-year survey. Iournal of Speech and Hearing Disorders, 51, 3-7.

Dublinski, S. (1981). Action school services. Speech Language Hearing Services in Schools, 12, 195.

Goldman, R., \& Fristoe, M. (1986). Goldman-Fristoe Test of Articulation. Circle Pines, MN: American Guidance Service.

Kenny, K., \& Prather, E. (1986). Articulation development in preschool children: Consistency of productions. Iournal of Speech and Hearing Research, 29, 29-36.

Leonti, S., Blakeley, R., \& Louis, H. (1975, November). Spontaneous correction of resistant $|3|, \& / r /$ using an oral prosthesis. Paper presented at the American Speech and Hearing Association Convention, Washington, D. C. 
McDonald, E. (1964). Articulation testing and treatment: A sensory-motor approach. Pittsburgh, PA: Stanwix House.

Monnin, L. (1984). Speech sound discrimination testing and training: Why? Why Not? In H. Winitz (Ed.), Treating articulation disorders (pp. 16-17). Baltimore, MD: University Park Press.

Neal, W. (1976). Speech pathology services in the secondary schools. Language, Speech, and Hearing Services in Schools, 7, 6-16.

Neidecker, E. (1987). School programs in speech language (2nd ed.). Englewood Cliffs, NJ: Prentice-Hall.

Portland Public Schools. (1986). The Speech and Language Severity Rating Scale Manual. Portland, OR: Portland Public Schools. Prather, E., Hedrick, D., \& Kern, C. (1975). Articulation development in children aged two to four years. Journal of Speech and Hearing Disorders, 40, 179-191.

Sander, E. (1972). When are speech sounds learned? Journal of Speech and Hearing Disorders, 37, 55-63.

Scripture E. (1975). Stuttering, lisping and correction of the speech of the deaf. New York: Macmillan.

Shriberg, L. (1975). A response evocation program for / $/$. Lournal of Speech and Hearing Disorders, $\underline{40}, 92-105$.

Shriberg, L. (1980). An intervention procedure for children with persistent / $r$ / errors. Language, Speech, and Hearing Services in Schools, 11, 102-110.

Shriberg, L., Kwiatkowski, J., Best, S., Hengst, J., \& Terselic-Weber, B. (1986). Characteristics of children with phonologic disorders of unknown origin. Journal of Speech and Hearing Disorders, $51,140-160$. 
Smit, A., Hand, L., Freilinger, J., Bernthal, J., \& Bird A. (1990). The Iowa articulation norms project and its Nebraska replication. Iournal of Speech and Hearing Disorders, 55, 779-798.

Silverman, F., \& Paulus, P. (1989). Peer reactions to teenagers who substitute $/ \mathrm{w} /$ for $/ \mathrm{r} /$. Language Speech Hearing Services in the Schools, 20, 219-221.

Stewart, S., Weybright, G. (1980). Articulation norms used by practicing speech-language pathologists in Oregon: Results of a survey. Lournal of Speech and Hearing Disorders, 45 , 103-111.

Templin, M. (1957). Certain language skills in children, their development and interrelationships. Institute of Child Welfare, Monograph Series, No. 26. Minneapolis: University of Minnesota Press.

Van Riper, C. (1972). Speech correction: Principles and methods. Englewood Cliffs, NJ: Prentice-Hall.

Weiss, C., Gordon, M., \& Lillywhite, H. (1987). Clinical management of articulatory and phonologic disorders. Baltimore, $\mathrm{OH}$ : Williams \& Wilkins.

Wellman, B., Case, I., Mengert, I., \& Bradbury, D. (1931). Speech sounds of young children. University of Iowa Studies on Child Welfare, $5,1-82$.

Wood, J. (1988). A clinical technique helpful in the elicitation of $/ 37$. Language, Speech and Hearing Services in Schools, 19, 96-99. Young, E., \& Hawk, S. (1938). Moto-kinesthetic speech training. Stanford, CA: Stanford University Press. 
APPENDIX A

LETTER TO PARENTS/ PERMISSION SLIP 


\section{LETTER TO PARENTS}

Date

Dear Mr/Ms

I am conducting a research project as part of a master's program at Portland State University, under the guidance of Mary Gordon-Brannan. Your school speech-language pathologist, has referred for this

project. The project will extend over a six week period beginning

participating. and ending There will be no cost to anyone

The purpose of this project is to help children who are misarticulating the $/ \mathrm{r} /$ sound, who have had past therapy, and who are still unable to correctly and consistently produce this sound. Two groups will be participating in the study. One group will be practicing their $/ \mathrm{r} /$ sound part of the time with an appliance (called an R-stick appliance) inserted in the roof of their mouth by the speech-language pathologist. This appliance is a piece of acrylic which is seated on the end of a stick. The purpose of the appliance is to facilitate the correct production of $/ \mathrm{r} /$. The other group in the project will continue with their current treatment program. However, if this appliance is successful in facilitating the $/ \mathrm{r} /$ sound, as we hope it will be, those children who did not receive the appliance during the program will have the option of receiving appliance treatment from their school clinician at the completion of the project.

The study will be carried out in your child's school with his/her present speech-language pathologist. His/her speech-language pathologist will be provided with special instructional materials and will see the child individually for two 30-minute sessions weekly.

During the course of the study, your child and his/her clinician will be audio tape recorded. This is necessary for certain data information and for reliability that the program was followed. To insure confidentiality, the audio tapes will be used only by the research personnel. In the written thesis, the child will be referred to by a subject number.

Participation in this project is voluntary. Because it is necessary to have a certain number of subjects in the research program, we hope that once your child has entered the project, he/she will continue in the program for eight weeks. However, the subject may discontinue participation at any time without penalty or loss of speech and language services. 
Page 2 Parent/Guardian Letter

Thank you in advance for allowing your child to help with some very valuable and much needed research. If you have any questions regarding this project feel free to call Mary Gordon-Brannan at 725-3533.

Sincerely,

Rosemary LeBlanc

School Speech-Language Pathologist 


\section{PERMISSION SLIP}

I to Rosemary LeBlanc to use my child/children (parent's, guardian's name) give permission (child's name) in her research study. I understand that if my child is accepted for this study that audio tape recordings will be used during the course of the study. Furthermore, I understand that the results of this study may be published and information and data gained will be shared with others. However, the children's names will not be used, and will only be referred to by number.

Parent/Guardian 
APPENDIX B

AUDITORY DISCRIMINATION TEST 


\section{AUDITORY DISCRIMINATION TEST}

(Clark, 1989)

Instructions: Below is a list of words. There are two words on each line. You are going to listen to a tape recording. You will be asked to CIRCLE the word you hear in each pair. Please listen carefully.

Practice items:

Bear

Pear

Tap

Cap

(BEGIN TAPE) CIRCLE THE WORD YOU HEAR
1. Way
Ray
2. Rain
Wane
3. Woe
Row
4. Ring
Wing
5. Wide
Ride
6. $\operatorname{Rod}$
Wad
7. Won
Run
8. Reek
Week
9. Whale
Rail
10. Rag
Wag
11. War
Roar
12. Rove
Wove
13. West
Rest
14. Rare
Wear
15. Witch
Rich 
APPENDIX C

PICTURE OF THE R-STICK APPLIANCE 


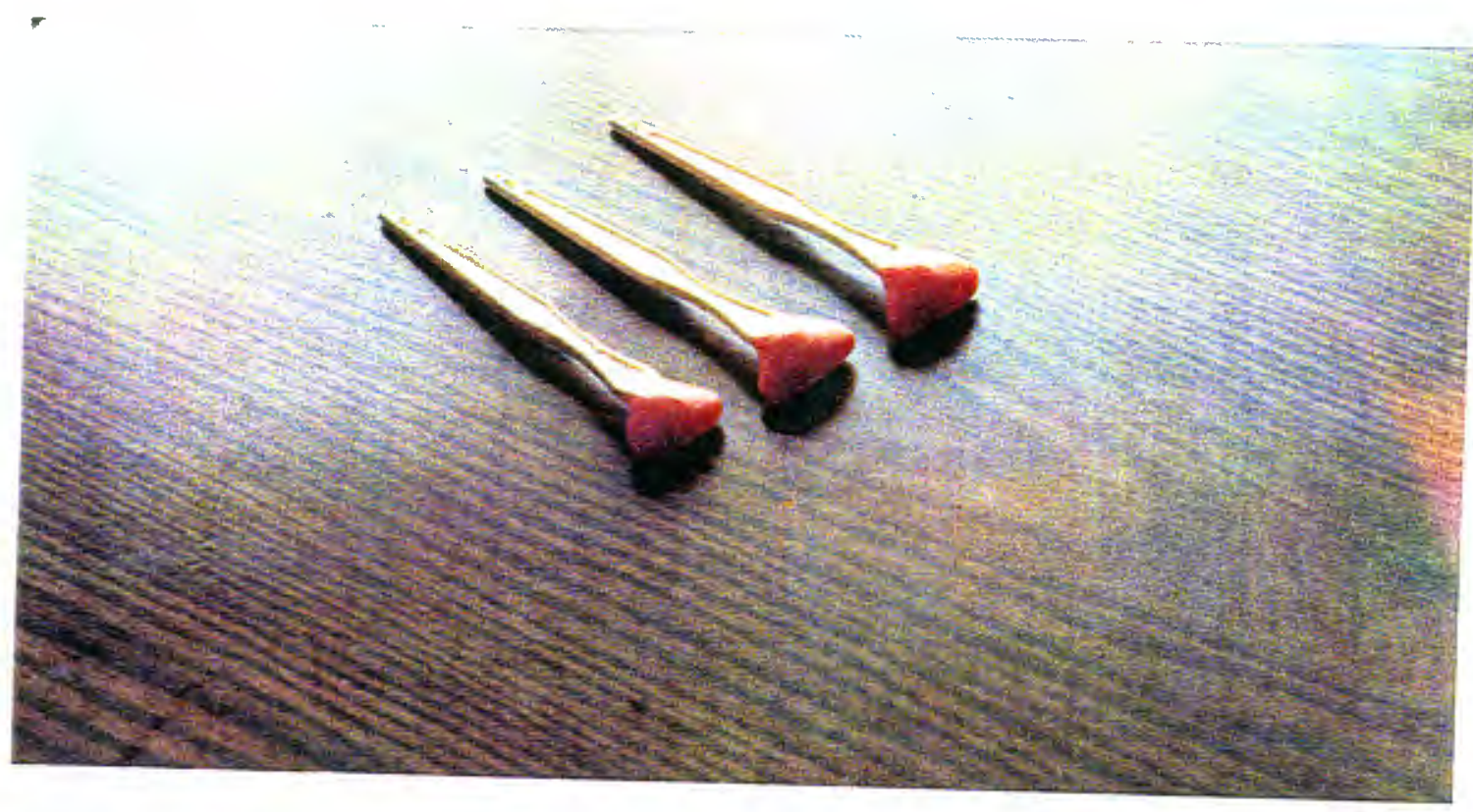


APPENDIX D

/ r/ PRETEST-POSTTEST LIST 
(Clark, 1989)

$\underline{10 \text { one syllable initial / } \mathrm{r} / \text { words }}$
1. rat
2. red
3. rain
4. rig
5. run
6. rang
7. rip
8. rake
9. rope
10. ring

10 two syllable medial / $\mathrm{r} /$ words

1. parent

2. very

3. arrow

4. forest

5. cherry

6. parrot

7. dairy

8. earring

9. sheriff

10. parade

10 one syllable final / $r$ / words

1. car

2. bear

3. fire

4. pear

5. more

6. bar

7. for

8. deer

9. care

10. ear
$10 \mathrm{r}$-blend words

1. broom

2. tricycle

3. drum

4. cross

5. bread

6. crown

7. frog

8. tree

9. dragon

10. fruit

10 stressed vocalic $|3|$

1. pearl

2. bird

3. girl

4. worm

5. nurse

6. turtle

7. shirt

8. curtain

9. fur

10. church

10 unstressed final $|\not{z}|$

1. diaper

2. butter

3. tiger

4. hanger

5. mother

6. washer

7. letter

8. hammer

9. fatter

10. water 
APPENDIX E

PROTOCOL FOR APPLIANCE PLACEMENT 


\section{PROTOCOL FOR APPLIANCE GROUP}

General information: The first steps with the appliance are critical to success.

General Instructions:

1. Please follow the protocol exactly so research will be valid.

2. You may decide the schedule for reinforcement during therapy sessions.

3. TAPE RECORD each session. Remember to give subject's number and the date of the session. This is very important for both data collection and reliability measures. THANKS!

Pre-program steps: TURN on the TAPE RECORDER

1. Before the appliance is in the mouth, tell the subject that you are going to ask him/her to make "noise". Demonstrate by making vowel noises (e.g. $/ \mathrm{i} /, / \mathrm{u} /$, ah). The purpose of this step is to show the subject what it is you want him/her to do when exploring for the $/ \mathrm{r} /$ sound.

2. Ask subject to do the same thing.

3. Then place appliance in the mouth.

4. Instruct subject to lift tongue up and back while making noise. Remind subject that sides of tongue need to touch the back teeth (make a wide or fat tongue). Make a noise back here (gesture to back of neck) or up here (gesture to top of head). Assistance may be given by touching the sides of the tongue and the alveolar ridge in the molar area and tipping or rolling the tongue tip back. Once the tongue is lifted up and back and the sides are pushing against the back teeth, if the sound continues to be "uh", have the subject hold that same position and tip the tongue-tip back (the dump trunk effect). Keep exploring for the correct tongue posture and correct sound. Reinforce close approximations while continuing to instruct in placement and sound.

5. Then have client produce it again. When he/she is able to produce the $/ \mathrm{r} /$ sound two or three times in a row, begin the program. 
Turn on Tape Recorder

\begin{tabular}{|c|c|c|c|}
\hline & $\begin{array}{l}\text { APPLIANCE IN } \\
\text { APPIIANCE OUT }\end{array}$ & & RITERIA for \\
\hline STEP & APPLIANCE OUT & PROCEDURE & \\
\hline 1 & Appliance IN & $/ \mathrm{r} /$ sound-isolation & $\begin{array}{l}9 / 10 \text { rest } 9 / 10 \\
\text { rest } 9 / 10\end{array}$ \\
\hline 2 & Appliance OUT & $/ \mathrm{r} /$ sound-isolation & $8 / 10$ \\
\hline 3 & \multicolumn{2}{|l|}{ Broken syllable } & $9 / 10$ for each one \\
\hline & $\begin{array}{ll}\mid \mathrm{r} / \text { + long a } 9 / 10 & \mid \mathrm{r} / \\
\mid \mathrm{r} / \text { + long e } 9 / 10 & \mid \mathrm{r} / \\
\mid \mathrm{r} / \text { + long i } 9 / 10 & / \mathrm{r} / \\
\mid \mathrm{r} / \text { + long o } 9 / 10 & \mid \mathrm{r} / \\
& \mid \mathrm{r} /\end{array}$ & $\begin{array}{l}\text { short a } 9 / 10 \\
\text { short e } 9 / 10 \\
\text { short i } 9 / 10 \\
\text { short o } 9 / 10 \\
\text { short u } 9 / 10\end{array}$ & \\
\hline
\end{tabular}

4. Appliance OUT $/ \mathrm{r} /+$ vowel $\quad 9 / 10$ for each one Broken syllable

$/ \mathrm{r} /$ + long a $9 / 10 / \mathrm{r} /+$ short a $9 / 10$

$/ \mathrm{r} /$ + long e $9 / 10 / \mathrm{r} /$ + short e $9 / 10$

$/ \mathrm{r} /$ + lone i $9 / 10 / \mathrm{r} /+$ short i $9 / 10$

$/ \mathrm{r} /+$ long o $9 / 10 / \mathrm{r} /+$ short $09 / 10$

$/ \mathrm{r} /+$ short $\mathrm{u} 9 / 10$

5. Appliance IN vowel $+/ r / \quad 9 / 10$ for each one Broken syllable

long $\mathrm{a}+/ \mathrm{r} / 9 / 10$ short $\mathrm{a}+/ \mathrm{r} / 9 / 10$

long $\mathrm{e}+/ \mathrm{r} / 9 / 10$ short $\mathrm{e}+/ \mathrm{r} / 9 / 10$

long $i+/ r / 9 / 10$ short $i+/ r / 9 / 10$

long $\mathrm{o}+/ \mathrm{r} / 9 / 10$ short $\mathrm{o}+/ \mathrm{r} / 9 / 10$

long $u+/ r / 9 / 10$ short $u+/ r / 9 / 10$

6. Appliance OU'T vowel $+/ \mathrm{r} / \quad 9 / 10$ for each one

\section{Broken syllable}

long $\mathrm{a}+/ \mathrm{r} / 9 / 10$ short $\mathrm{a}+/ \mathrm{r} / 9 / 10$

long $\mathrm{e}+/ \mathrm{r} / 9 / 10$ short $\mathrm{e}+/ \mathrm{r} / 9 / 10$

long $i+/ r / 9 / 10$ short $i+/ r / 9 / 10$

long $\mathrm{o}+/ \mathrm{r} / 9 / 10$ short $\mathrm{o}+/ \mathrm{r} / \mathrm{g} / 10$

long $\mathrm{u}+/ \mathrm{r} / 9 / 10$ short $\mathrm{u}+/ \mathrm{r} / 9 / 10$ 
7. Appliance IN

$/ \mathrm{r} / \sim$ long a $9 / 10$

Blended / $\mathrm{r} /$ + vowel

$9 / 10$ for each one

$/ \mathrm{r} / \sim$ long e $9 / 10$

$/ \mathrm{r} / \sim$ short a $9 / 10$

$/ \mathrm{r} / \sim$ long $\mathrm{i} 9 / 10$

$/ \mathrm{r} / \sim$ short e $9 / 10$

$/ \mathrm{r} / \sim$ long o $9 / 10$

$/ \mathrm{r} / \sim \operatorname{shorti} 9 / 10$

$/ \mathrm{r} / \sim$ short o $9 / 10$

$/ \mathrm{r} / \sim \operatorname{short} \mathrm{u} 9 / 10$

8. Appliance OUT

Blended $/ \mathrm{r} /$ + vowel

9/10 for each one

$\mid \mathrm{r} / \sim$ long a $9 / 10$

$/ \mathrm{r} / \sim$ long e $9 / 10$

$/ \mathrm{r} / \sim \operatorname{short}$ a $9 / 10$

$/ \mathrm{r} / \sim$ long $\mathrm{i} 9 / 10$

$/ \mathrm{r} / \sim$ short e $9 / 10$

$/ \mathrm{r} / \sim$ long o $9 / 10$

$/ \mathrm{r} / \sim$ short i $9 / 10$

$/ \mathrm{r} / \sim \operatorname{short}$ o $9 / 10$

$/ \mathrm{r} / \sim$ short $\mathrm{u} 9 / 10$

9. Appliance IN

long $a \sim / r / 9 / 10$

Blended vowel $\sim / \mathrm{r}$

long $\mathrm{e} \sim / \mathrm{r} / 9 / 10$

short $\mathrm{a} \sim / \mathrm{r} / 9 / 10$

long $i \sim / r / 9 / 10$

long $o \sim / r / 9 / 10$

long $\mathrm{u} \sim / \mathrm{r} / 9 / 10$

short $\mathrm{e} \sim / \mathrm{r} / 9 / 10$

short $i \sim / r / 9 / 10$

short $0 \sim / r / 9 / 10$

short $u \sim / r / 9 / 10$

10. Appliance OUT long $\mathrm{a} \sim / \mathrm{r} / \mathrm{9} / 10$ long $\mathrm{e} \sim / \mathrm{r} / \mathrm{9} / 10$ Blended vowel $\sim / \mathrm{r} /$

short $\mathrm{a} \sim / \mathrm{r} / 9 / 10$

short $\mathrm{e} \sim / \mathrm{r} / 9 / 10$

long $\mathrm{i} \sim / \mathrm{r} / \mathrm{9} / 10$

short $\mathrm{i} \sim / \mathrm{r} / \mathrm{g} / 10$

long $\mathrm{u} \sim / \mathrm{r} / 9 / 10$

short $\mathrm{u} \sim / \mathrm{r} / 9 / 10$

11 Appliance IN

12 Appliance OUT

Words-/r/-initial(ran)

$18 / 20$

Words-/r/-initial

$9 / 10$ for each one

13 Appliance IN

Words-/ $\mathrm{r} /$-medial(berry)

$18 / 20$

Words-/r/-medial

$18 / 20$

Words-/ $\mathrm{r} /$-final(car)

$18 / 20$

15 Appliance IN

Words-/ $\mathrm{r} /$-final

$18 / 20$

Words- $/ \mathrm{r} /$-vocalic stressed $18 / 20$

17 Appliance IN

Words- $/ \mathrm{r} /$-vocalic stressed

$18 / 20$

Words-/r/-vocalic stressed

$18 / 20$

Words-/r/-unstressed $\quad 18 / 20$

Words-/r/-unstressed $\quad 18 / 20$

Words-/r/-random sample $18 / 20$

20 Appliance OUT

Appliance IN

22

Appliance OUT

Words-/r/-random sample

$18 / 20$ 